\title{
BMJ Open First steps in the physician-scientist pipeline: a longitudinal study to examine the effects of an undergraduate extracurricular research programme
}

\author{
Belinda W C Ommering (D) , ${ }^{1}$ Floris M van Blankenstein, ${ }^{1}$ Friedo W Dekker ${ }^{2}$
}

To cite: Ommering BWC, van Blankenstein FM, Dekker FW. First steps in the physician-scientist pipeline: a longitudinal study to examine the effects of an undergraduate extracurricular research programme. BMJ Open 2021;11:e048550. doi:10.1136/ bmjopen-2020-048550

- Prepublication history and additional supplemental material for this paper are available online. To view these files, please visit the journal online (http://dx.doi.org/10.1136/ bmjopen-2020-048550)

Received 30 December 2020 Accepted 18 August 2021
A) Check for updates

(c) Author(s) (or their employer(s)) 2021. Re-use permitted under CC BY-NC. No commercial re-use. See rights and permissions. Published by BMJ.

${ }^{1}$ Center for Innovation in Medical Education, Leiden University Medical Center, Leiden, The Netherlands

${ }^{2}$ Department of Clinical Epidemiology, Leiden University Medical Center, Leiden, The Netherlands

Correspondence to Belinda W C Ommering; b.w.c.ommering@lumc.nl

\section{ABSTRACT}

Objectives Medicine is facing a physician-scientist shortage. By offering extracurricular research programmes (ERPs), the physician-scientist training pipeline could already start in undergraduate phases of medical training. However, previous studies into the effects of ERPs are mainly retrospective and lack baseline measurements and control groups. Therefore, the current study mimics a randomised controlled trial to examine the effects of an ERP.

Design Prospective cohort study with baseline measurement and comparable control group.

Setting One cohort of 315 medical undergraduates in one Dutch University Medical Center are surveyed yearly. To examine the effects of the ERP on academic achievement and motivational factors, regression analyses were used to compare ERP students to students showing ERP-interest only, adjusted for relevant baseline scores.

Participants Out of the 315 students of the whole cohort, 56 participated within the ERP and are thus included. These ERP students are compared with 38 students showing ERP-interest only (ie, control group).

Primary outcome measure Academic achievement after 2 years (ie, in-time bachelor completion, bachelor grade point average (GPA)) and motivational factors after 18 months (ie, intrinsic motivation for research, research selfefficacy, perceptions of research, curiosity).

Results ERP participation is related to a higher odds of obtaining a bachelor degree in the appointed amount of time (adjusted OR=2.95, 95\% $\mathrm{Cl} 0.83$ to 10.52 ). Furthermore, starting the ERP resulted in higher levels of intrinsic motivation for research, also after adjusting for gender, age, first-year GPA and motivational baseline scores ( $\beta=0.33,95 \% \mathrm{Cl} 0.04$ to 0.63 ). No effect was found on research self-efficacy beliefs, perceptions of research and curiosity.

Conclusions Previous research suggested that intrinsic motivation is related to short-term and long-term research engagement. As our findings indicate that starting the ERP is related to increased levels of intrinsic motivation for research, ERPs for undergraduates could be seen as an important first step in the physician-scientist pipeline.

\section{INTRODUCTION}

The field of medicine is dynamic with many remaining 'unknowns'. In order to unravel the

\section{Strengths and limitations of this study}

- This is one of the first studies to use a prospective study design including a baseline measure and comparable control group to examine the effects of an extracurricular research programme (ERP).

- This study complies to the need to investigate the effects of ERPs on both academic achievement and motivational factors using a longitudinal design.

- Previous research relies mainly on a retrospective approach from which causality cannot be inferred.

- Although observational in nature as randomisation is not possible within this context, this study tried to mimic a randomised controlled trial by comparing students starting the ERP to students showing interest only.

- This was a single-institute study and generalisability beyond universities with the same structure and research intensive characteristics needs further study.

unknown and make advancements within the medical domain, research is key. However, to actually benefit patient care, research should be connected to clinical practice. That is, relevant questions and problems originating from daily clinical practice should be identified and translated into research designs (ie, connecting bedside to bench) and research outcomes should be translated into daily practice (ie, connecting bench to bedside). Within this process of translational research, physician-scientists play a crucial role. ${ }^{1-4}$ Physician-scientists are healthcare professionals investing a solid amount of their time in both research and clinical duties, and are therefore in the unique position to connect bedside to bench and vice versa. ${ }^{45}$

Unfortunately, many concerns have been raised regarding the future of the physicianscientist workforce. As a result of the rising age of the current workforce, attrition from the physician-scientist training pipeline, and a decreasing interest to even pursue this pipeline or a scientific career, medicine 
is currently facing a physician-scientist shortage. ${ }^{6-9} \mathrm{~A}$ possible solution to foster the physician-scientist workforce is to engage medical students in research in the early phases of medical school. Research engagement of medical students is related to research involvement further in medical training and in future professional practice. ${ }^{10}{ }^{11}$ As a result of engaging in research during medical training, students become aware of and motivated for research, possibilities for a research career are identified, and research talent is recognised by medical professionals. ${ }^{12}$ In this way, the physician-scientist training pipeline could already start in undergraduate and preclinical phases of medical training. To this end, many medical schools have created scholarly programmes, both intracurricular and extracurricular. ${ }^{6} 813$ Although extracurricular research programmes (ERPs) occur under diverse names, for example, scholarly concentration programmes, capstone programmes, summer schools and honours programmes, they do share the common goal to engage students in research and cultivate future physician-scientists.

Within the past decades, many research initiatives emerged aiming to map the effects of ERPs. For instance, Wolfson et al showed that both satisfaction within a scholarly concentration programme and publication in scientific journals as a result of programme participation were related to an enhanced career-long research interest. ${ }^{6}$

A retrospective study by Radville et al suggested that graduates who participated in a scholarly concentration programme are more likely to stay scientifically active, as they published more after graduating and more frequently took on an academic health centre job. ${ }^{14} \mathrm{~A}$ recent study by DiBiase et al also showed that participation in a scholarly concentration programme is related to increased levels of research self-efficacy, which in turn is related to an enhanced intention to pursue scientific work. ${ }^{15}$

However, within a systematic review, it was concluded that most studies into ERPs have a retrospective design and evidence for the effect of such programmes resulting from rigorous study designs is lacking. ${ }^{16}$ After using the Medical Education Research Study Quality Instrument, the authors concluded that the included studies scored low on study design and validity and called for studies with more rigorous study designs. ${ }^{16}$ More specifically, very few studies have investigated the effects of ERPs on both academic achievement and motivational factors using a longitudinal design. ${ }^{17}$ As grades do not by definition reflect all valued skills of future physicians, it seems beneficial to focus on more than just academic performance as an outcome measure. In addition, students choosing to participate in ERPs are believed to differ from students not following this path. Therefore, a sound baseline measure is needed for which a prospective study is a good approach. Finally, a comparable control group of students who are not participating in the ERP is absent in most studies as well. In these cases, the question arises if students would have developed in similar ways within the regular educational programme. ${ }^{81617}$

The current study therefore combines a prospective, longitudinal study design with a sound baseline measure and comparable control group to answer the following research question: "what is the effect of an ERP on academic achievement, intrinsic motivation for research, research self-efficacy beliefs, perceptions of research and curiosity'. Although with 18 months follow-up these are relatively short-term measures of research engagement, existing theories and previous studies indicate that these constructs are related to long-term research engagement and scholarly output. ${ }^{10}{ }^{11} 18-21$ Furthermore, keeping in mind that grades do not necessarily align with all valued skills as a future physician or physician-scientist, we specifically focused on more than just academic achievement. As the pre-eminent goal of ERPs is to cultivate future physician-scientists, intrinsic motivation for research, research self-efficacy beliefs, perceptions of research and curiosity may be seen as key outcome objectives, especially as they are related to future research involvement. ${ }^{10} 11$ 18-21

\section{METHOD}

\section{Context}

Leiden University Medical Center (LUMC) is one of eight universities within the Netherlands offering medical education, in line with the Dutch National Blueprint for Medical Education that is based on the CanMEDS. ${ }^{22} 23$ Consequently, the structure of medical education is comparable in all universities with a 6-year undergraduate educational programme. In addition to the core curriculum, LUMC implemented an ERP (ie, research-based honours programme) aiming to foster research talent and cultivate future physician-scientists. The programme, starting in the second year of undergraduate medical education, provides students with opportunities to conduct research individually. Programme duration is 2years and selection is mainly based on self-selection without very strict institutional criteria. Thus, every student can apply. As a result, approximately 50-60 motivated students start in the programme each year, representing $15 \%-20 \%$ of the whole second-year cohort of medical students. To get a certificate for this programme, students need to obtain 30 extra credits (ECTS, ie, European Credit Transfer and Accumulation System, which means that students have to invest $30 \times 28$ hours of active study). At the same time, they have to obtain 180 regular ECTS for their 3-year bachelor programme with a grade point average (GPA) of at least 7 on a 10-point grading scale. ${ }^{24}$

\section{Design and participants}

Within a longitudinal, prospective study design, one complete cohort of medical undergraduates was followed for 3 years. Every student starting medical school at the LUMC in 2016 was asked to participate and data were gathered longitudinally by surveying participants each year (ie, November 2016, January 2018 and December 2018). 
Ideally, one would aspire a randomised controlled trial (RCT) in order to examine the effects of the ERP, dividing students who expressed interest in the programme in a participating and a non-participating group at random. However, as randomisation is not possible here, we tried to mimic an RCT by comparing students starting the ERP to students that have shown interest in the ERP, but eventually decided not to participate. Furthermore, we adjusted for potentially relevant baseline differences to make the groups as comparable as possible.

\section{Materials and definitions}

The effects of the ERP were examined by comparing the two groups of students on academic achievement 2 years later and motivational factors 18 months later, while adjusting for relevant baseline scores. Motivational factors consisted of intrinsic motivation for research, research self-efficacy beliefs, perceptions of research and curiosity.

Academic achievement was operationalised as students' in-time bachelor completion and bachelor GPA, which were both drawn from university files. For the motivational outcome measures, questionnaire data were used. ${ }^{10}$ Existing and validated scales were used to compose the questionnaire, though adjusted to the medical education setting and focusing on conducting research (online supplemental appendix A). Students scored the items on a 7-point Likert scale ranging from 1-'totally disagree' to 7-'totally agree'. Intrinsic motivation for research was defined as motivation to conduct research out of pure enjoyment or interest. The scale consisted of five items (eg, 'doing research is fun'), derived from the Interest/ Enjoyment Scale of the Self-Determination Questionnaires. ${ }^{25}$ Research selfefficacy was defined as students' beliefs about their own abilities to conduct research. This self-developed scale consisted of three items (eg, 'I feel I am competent enough to do research') and was inspired by the Dutch General Self-Efficacy Scale and the Academic Efficacy Scale. ${ }^{26} 27$ Perceptions of research was defined as students' beliefs about the value of research. The scale consisted of five items (eg, 'It is important for medical professionals to have scientific skills'), derived from the Student Perception of Research Integration Questionnaire. ${ }^{28}$ Curiosity was defined as students' desire for knowledge, promoting learning of new ideas and solving intellectual problems. The scale consisted of ten items (eg, 'I enjoy investigating new ideas') of the Epistemic Curiosity Scale. ${ }^{29}$

\section{Procedure}

The existing scales were adjusted to fit our setting, after which we used the forward and backward translation procedure to translate the questionnaire from English to Dutch. The questionnaire was pretested among 10 medical students in their second year of undergraduate medical education, after which two minor adjustments were made to two items. For the actual longitudinal study, every student entering medical education in 2016 was approached by a member of the research team during a mandatory workgroup session in one of the first courses of the educational programme (baseline T1-November 2016). These students were surveyed again in the first semester of their second (T2-January 2018) and third year (T3-December 2018) of undergraduate medical education. An overview of the timeline is illustrated in figure 1 . The goals and voluntary nature of participation in this study were communicated to students and it was explained that all data would be processed anonymously and used for research purposes only. Students filled in an informed consent form, approving to connect data of the questionnaires (T1, T2, T3) and the academic achievement components.

\section{Analyses}

Descriptive statistics were used to report participants' demographics and Cronbach's alpha was calculated to estimate the reliability of the questionnaire scales. Mean scores were calculated for the motivational factors. Missing data were handled by using multiple imputation. ${ }^{30}$ Univariate and multivariate logistic and linear regressions were used to compare students within the programme to the control group outside of the programme on academic achievement, intrinsic motivation for research, research self-efficacy beliefs, perceptions of research and curiosity. Within the multivariate regressions, we adjusted for potential confounding factors: gender, age, T1 baseline scores of all motivational outcome measures and first-year GPA (ie,
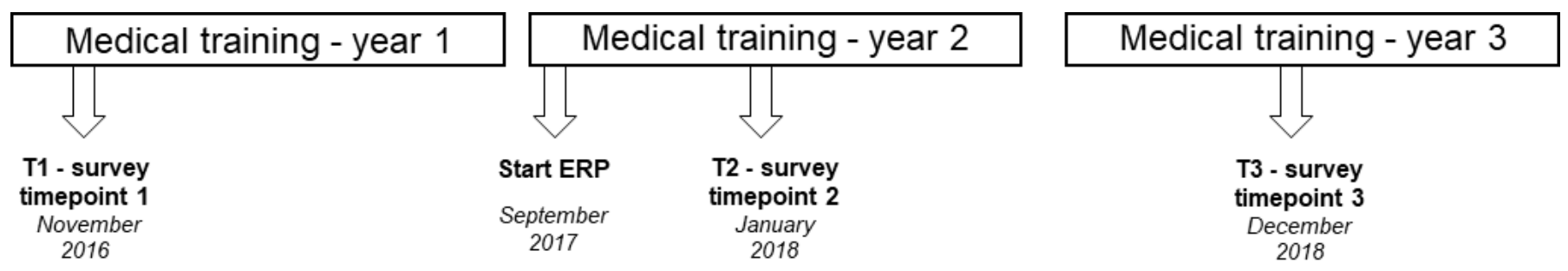

First-year GPA

Extracurricular Research Programme

September 2016 - July 2017

September 2017 - July 2019

Figure 1 Timeline illustrating extracurricular research programme (ERP) start, ERP duration and survey measurements. GPA, grade point average. 
covering the period before starting the ERP). Results are presented with $95 \%$ CIs. We analysed all data using IBM SPSS Statistics V.23.

\section{Patient and public involvement}

No patients involved.

\section{RESULTS}

Out of in total 315 medical students, 94 students were included within the current study, of whom 56 started in the ERP (59.6\%). The remaining 38 students (40.4\%) showed interest in the ERP without self-selecting themselves and actually participating, thus serving as the comparable control group within our study. Of the 56 students starting the programme, 43 students were female $(76.8 \%)$ and 13 students were male $(23.2 \%)$ with a mean age of $18.5(\mathrm{SD}=0.91)$ years. The control group comprised 30 female $(78.9 \%)$ and 8 male students $(21.1 \%)$ with a mean age of $18.6(\mathrm{SD}=1.28)$ years. Baseline scores of both groups on first-year GPA and the motivational factors can be found in table 1 . Cronbach's alpha of the scales ranged from 0.78 to 0.86 at $\mathrm{T} 1$ baseline (first year of medical training-November 2016), 0.79 to 0.86 at T2 (second year of medical training - January 2018) and 0.82 to 0.89 at T3 (third year of medical training-December 2018). In-time bachelor completion, third-year GPA, and T3 scores on intrinsic motivation for research, research selfefficacy beliefs, perceptions of research and curiosity are reported in table 2 .

\section{Academic achievement}

A crude effect of starting the ERP on in-time bachelor completion was found, showing that students starting the programme had higher odds of obtaining their bachelor degree in time $(\mathrm{OR}=3.64,95 \%$ CI 1.29 to 10.27$)$, also after adjusting for gender, age, first-year GPA and all $\mathrm{T} 1$ baseline scores $(\mathrm{OR}=2.95,95 \%$ CI 0.826 to 10.52$)$. Participating in the ERP, on its own, had an effect on students' bachelor GPA ( $\beta=0.299,95 \%$ CI 0.097 to 0.500$)$. After adjusting for gender, age, first-year GPA and all T1 baseline scores the effect disappeared ( $\beta=-0.026$, 95\% CI -0.160 to 0.108$)$.

\section{Motivational factors}

There was a positive effect of starting the ERP on intrinsic motivation for research in the third year of medical training ( $\beta=0.462,95 \%$ CI 0.113 to 0.811$)$, also after adjusting for gender, age, all T1 baseline scores and firstyear GPA ( $\beta=0.334,95 \%$ CI 0.042 to 0.627 ). Students starting the programme report higher levels of intrinsic motivation for research in their third year of medical training. Starting in an ERP did not, however, have an effect on research self-efficacy beliefs, perceptions of research and curiosity. An overview of these findings can be found in table 3 .
Table 1 Baseline characteristics divided by students entering the extracurricular research programme (ERP) and students showing interest without entering the ERP $(n=94)$

\begin{tabular}{|c|c|c|}
\hline & $\begin{array}{l}\text { Non-ERP } \\
\mathrm{n}=38\end{array}$ & $\begin{array}{l}\text { ERP } \\
n=56\end{array}$ \\
\hline \multicolumn{3}{|l|}{ Gender } \\
\hline Male & $8(21.1 \%)$ & $13(23.2 \%)$ \\
\hline Female & $30(78.9 \%)$ & $43(76.8 \%)$ \\
\hline \multicolumn{3}{|l|}{ Age } \\
\hline $\mathrm{M}(\mathrm{SD})$ & $18.63(1.28)$ & $18.45(0.91)$ \\
\hline Min-max & $16-23$ & $17-21$ \\
\hline \multicolumn{3}{|c|}{ First-year GPA } \\
\hline $\mathrm{n}$ & 38 & 56 \\
\hline $\mathrm{M}(\mathrm{SD})$ & $6.76(0.45)$ & $7.18(0.55)$ \\
\hline Min-max & $6.0-8.1$ & $6.4-8.9$ \\
\hline \multicolumn{3}{|c|}{ Intrinsic motivation T1 } \\
\hline $\mathrm{n}$ & 38 & 56 \\
\hline $\mathrm{M}(\mathrm{SD})$ & $5.67(0.56)$ & $5.84(0.69)$ \\
\hline Min-max & $4.8-7.0$ & $4.2-7.0$ \\
\hline \multicolumn{3}{|c|}{ Research self-efficacy T1 } \\
\hline $\mathrm{n}$ & 37 & 56 \\
\hline $\mathrm{M}(\mathrm{SD})$ & $5.05(0.96)$ & $5.13(0.97)$ \\
\hline Min-max & $3.0-6.7$ & $3.0-7.0$ \\
\hline \multicolumn{3}{|c|}{ Perceptions of research T1 } \\
\hline$n$ & 38 & 56 \\
\hline $\mathrm{M}(\mathrm{SD})$ & $5.68(0.67)$ & $5.87(0.79)$ \\
\hline Min-max & $4.4-7.0$ & $2.8-7.0$ \\
\hline \multicolumn{3}{|l|}{ Curiosity $\mathrm{T} 1$} \\
\hline$n$ & 38 & 56 \\
\hline $\mathrm{M}(\mathrm{SD})$ & $5.37(0.66)$ & $5.46(0.69)$ \\
\hline Min-max & $4.3-6.8$ & $4.1-6.9$ \\
\hline
\end{tabular}

GPA, grade point average.

\section{DISCUSSION}

Within this study, we compared students starting an ERP with students that have shown interest in the same ERP, but eventually decided not to participate. By using a longitudinal study design with a sound baseline measure and a comparable control group, we aimed to map the effects of an ERP. With regard to academic achievement, our findings suggest that starting the ERP leads to higher odds of obtaining a bachelor degree in the appointed amount of time. When it comes to the motivational factors included in our study, our findings showed that starting the ERP only affected levels of intrinsic motivation for research significantly, as students starting the programme reported higher levels of intrinsic motivation for research in the third year of medical training. No effect was found on research self-efficacy beliefs, perceptions of research and curiosity. 
Table 2 Descriptives of outcome measures divided by non-ERP students and ERP students ( $n=94$ for academic measures and $n=82$ for motivational measures)

\begin{tabular}{|c|c|c|}
\hline & Non-ERP & ERP \\
\hline \multicolumn{3}{|c|}{ In-time bachelor completion } \\
\hline In time & $25(65.8 \%)$ & $49(87.5 \%)$ \\
\hline Delay & $13(34.2 \%)$ & 7 (12.5\%) \\
\hline \multicolumn{3}{|c|}{ Bachelor GPA } \\
\hline$n$ & 38 & 56 \\
\hline $\mathrm{M}(\mathrm{SD})$ & $6.93(0.47)$ & $7.23(0.50)$ \\
\hline Min-max & $6.0-8.1$ & $6.3-8.9$ \\
\hline \multicolumn{3}{|c|}{ Intrinsic motivation T3 } \\
\hline$n$ & 30 & 52 \\
\hline $\mathrm{M}(\mathrm{SD})$ & $5.36(0.78)$ & $5.85(0.62)$ \\
\hline Min-max & $2.8-6.4$ & $4.0-7.0$ \\
\hline
\end{tabular}

Research self-efficacy T3

\begin{tabular}{lll}
$\mathrm{n}$ & 30 & 52 \\
$\mathrm{M}(\mathrm{SD})$ & $4.81(1.16)$ & $4.85(0.90)$ \\
\hline $\begin{array}{l}\text { Min-max } \\
\text { Perceptions of research T3 }\end{array}$ & $1.7-7.0$ & $2.0-7.0$ \\
$\mathrm{n}$ & 30 & \\
\hline M (SD) & $5.41(0.76)$ & $5.58(0.84)$ \\
\hline Min-max & $4.0-7.0$ & $3.8-7.0$ \\
Curiosity T3 & & \\
\hline $\mathrm{n}$ & 30 & 52 \\
\hline M (SD) & $5.22(0.71)$ & $5.37(0.66)$ \\
\hline Min-max & $4.0-6.7$ & $3.8-6.9$ \\
\hline
\end{tabular}

ERP, extracurricular research programme; GPA, grade point average.

With regard to academic achievement, our findings suggest that starting an ERP increases the odds of obtaining a bachelor degree in time. From a statistical perspective, this effect is borderline non-significant. There is a broad

Table 3 Regression model of the effect of starting the extracurricular research programme on the motivational factors in the third year of medical education (T3)

\begin{tabular}{lll}
\hline & $\begin{array}{l}\text { Crude } \\
\boldsymbol{\beta}(\mathbf{9 5 \%} \mathbf{C l}), \boldsymbol{p} \text { value }\end{array}$ & $\begin{array}{l}\text { Adjusted }^{*} \\
\boldsymbol{\beta} \text { (95\% } \mathbf{C l}), \boldsymbol{p} \text { value }\end{array}$ \\
\hline Intrinsic & $0.462(0.113$ to 0.811$)$, & $0.334(0.042$ to 0.627$)$, \\
motivation & 0.010 & 0.025 \\
Research & $0.108(-0.417$ to 0.634$)$, & $0.015(-0.439$ to 0.469$)$, \\
self-efficacy & 0.684 & 0.949 \\
Perceptions & $0.208(-0.203$ to 0.619$)$, & $0.080(-0.109$ to 0.269$)$, \\
of research & 0.320 & 0.673 \\
Curiosity & $0.136(-0.163$ to 0.436$)$, & $0.113(-0.173$ to 0.400$)$, \\
& 0.372 & 0.449 \\
\hline
\end{tabular}

*Adjusted for age, gender, motivational baseline scores (ie, intrinsic motivation for research, research self-efficacy beliefs, perceptions of research, curiosity) and first-year grade point average.
CI, resulting in some uncertainty regarding the exact size of the effect. However, the best estimate is a strong and relevant effect, as the OR of 2.95 suggests that the odds of success (ie, in-time bachelor completion) is almost three times as high when students start the ERP. Starting the programme did not, however, have a beneficial effect on bachelor GPA. As the crude effect on bachelor GPA disappears after adjusting for first-year GPA, it can be assumed that students' first-year GPA is a confounder related to their choice to participate within an ERP as well as related to their subsequent bachelor GPA.

More importantly, when focusing on the aim of ERPs, our findings suggest there was an effect of the ERP on levels of intrinsic motivation for research in the third year of medical training. According to the self-determination theory, intrinsic motivation (ie, doing an activity out of pure interest or enjoyment) is related to better academic performances and general well-being. Furthermore, we already know that intrinsic motivation for research is related to actual involvement in research during medical training, ${ }^{10}$ which in turn is related to research involvement in future professional practice. ${ }^{1131}$ Moreover, results of a scoping review reveal that it is especially intrinsic motivation among professionals that influences scientific career progression. ${ }^{32}$ These theoretical and scientific notions contribute to the perspective that intrinsic motivation for research is a key component in order to foster future physician-scientists.

Interestingly, however, the ERP had no effect on the other motivational factors that we measured. Our results suggest that starting the programme does not significantly increase levels of research self-efficacy among students. This contradicts findings from a recent study, showing that participation in a scholarly concentration programme was related to higher levels of research self-efficacy. ${ }^{15}$ However, as the scholarly concentration programme in that study was a mandatory part of medical training, a control group consisting of students not following the programme was absent, making it more difficult to attribute the higher levels of self-efficacy to participating in that specific programme. A possible explanation could be that participating students, while receiving in-depth research experiences, become aware that the process of conducting research could be time-consuming and hard, as is also acknowledged by our students already in their first-year of medical training. ${ }^{18}$ In turn, this could diminish feelings of success, which according to the social cognitive theory is related to levels of self-efficacy. ${ }^{20}$

Our findings also suggest that there is no effect of the ERP on perceptions of research. Perceptions of research are believed to be related to an apparent connection of research to practice, ${ }^{18}$ it could be that this connection to clinical practice is lacking for these young students while submerging in the world of research. It could also be that a course in the first-year of medical training in which students actively conduct research individually, as is implemented by LUMC, contributed to a broad perspective on research and already very positive perceptions of 
research before starting the ERP in the second year of medical training. ${ }^{18}$

Our findings are partly in line with a previous study of Kool and colleagues, in which no effect of participation within an extracurricular programme was found on ability, creativity and motivation. The reason mentioned for the absence of these effects was that their post-measure was 6 months after starting the extracurricular programme, which might have been too soon to note changes in ability, creativity and motivation. ${ }^{17}$ Our outcome measures were examined 18 months after starting the ERP. Although this might have been too short-term to identify increasing levels of research self-efficacy, perceptions of research and curiosity, we did find a positive effect on intrinsic motivation for research. The ERP can thus be viewed as a way to enhance intrinsic motivation for research and subsequently a first step in the physician-scientist pipeline.

\section{Limitations, strengths and future research}

This was a single-institute study which might impact generalisability to other contexts. However, as (1) our educational programme is based on the Dutch National Blueprint for Medical Education, which is an adaptation from the CanMEDS and (2) many medical schools offer ERPs to undergraduate medical students, we believe our findings might be translated to other educational contexts as well. Our study is one of the first to use a longitudinal, prospective study design with a sound baseline measure and comparable control group to examine both academic and motivational effects as a result of starting an ERP. Future research could focus on identifying how levels of research self-efficacy, perceptions and curiosity could be increased within the programme, using quantitative and qualitative methods to, for instance, uncover the effect of mentorship and success experiences on the abovementioned motivational factors. Furthermore, we established an effect on intrinsic motivation for research 18 months after starting the ERP. Although theoretical and scientific notions corroborate the assumption that this will be related to research engagement even further in the physician-scientist pipeline, a relevant future research avenue could be to investigate if the effect persists. Subsequently, evidence-based strategies could then be implemented to enlarge the short-term and longterm effects of ERP participation aiming to foster future physician-scientists.

\section{CONCLUSION}

Previous research suggested that intrinsic motivation for research is an important incentive for research engagement during medical training and future professional practice. As we have shown now that starting in an ERP is related to increased levels of intrinsic motivation for research, such programmes for undergraduates could be seen as a valuable first step in the physician-scientist pipeline.
Twitter Belinda W C Ommering @b_ommering

Contributors BWCO, FMvB and FWD contributed to the design of the study. BWCO performed the data analysis. FWD supervised data analysis. BWCO and FWD interpreted the data. BWCO wrote the manuscript. All authors contributed to the revision of the manuscript and approved the final version for publication.

Funding The authors have not declared a specific grant for this research from any funding agency in the public, commercial or not-for-profit sectors.

Competing interests None declared.

Patient consent for publication Not required.

Ethics approval The study was approved by the ethical review board of the Netherlands Association for Medical Education: reference number 952.

Provenance and peer review Not commissioned; externally peer reviewed. Data availability statement No data are available.

Supplemental material This content has been supplied by the author(s). It has not been vetted by BMJ Publishing Group Limited (BMJ) and may not have been peer-reviewed. Any opinions or recommendations discussed are solely those of the author(s) and are not endorsed by BMJ. BMJ disclaims all liability and responsibility arising from any reliance placed on the content. Where the content includes any translated material, BMJ does not warrant the accuracy and reliability of the translations (including but not limited to local regulations, clinical guidelines, terminology, drug names and drug dosages), and is not responsible for any error and/or omissions arising from translation and adaptation or otherwise.

Open access This is an open access article distributed in accordance with the Creative Commons Attribution Non Commercial (CC BY-NC 4.0) license, which permits others to distribute, remix, adapt, build upon this work non-commercially, and license their derivative works on different terms, provided the original work is properly cited, appropriate credit is given, any changes made indicated, and the use is non-commercial. See: http://creativecommons.org/licenses/by-nc/4.0/.

ORCID iD

Belinda W C Ommering http://orcid.org/0000-0002-8673-4923

\section{REFERENCES}

1 Salata RA, Geraci MW, Rockey DC, et al. U.S. Physician-Scientist workforce in the 21st century: recommendations to attract and sustain the pipeline. Acad Med 2018;93:565-73.

2 Woolf $\mathrm{SH}$. The meaning of translational research and why it matters. JAMA 2008;299:211-3.

3 Butler D. Translational research: crossing the Valley of death. Nature 2008;453:840-2.

4 Weggemans MM, Friesen F, Kluijtmans M, et al. Critical gaps in understanding the Clinician-Scientist workforce: results of an international expert meeting. Acad Med 2019;94:1448-54.

5 Sklar DP. We must not let clinician-scientists become an endangered species. Acad Med 2017;92:1359-61.

6 Wolfson RK, Alberson K, McGinty M, et al. The impact of a scholarly concentration program on student interest in Career-Long research: a longitudinal study. Acad Med 2017;92:1196-203.

7 Hall AK, Mills SL, Lund PK. Clinician-investigator training and the need to pilot new approaches to recruiting and retaining this workforce. Acad Med 2017;92:1382-9.

8 Chang Y, Ramnanan CJ. A review of literature on medical students and scholarly research: experiences, attitudes, and outcomes. Acad Med 2015;90:1162-73.

9 NIH. Physician-scientist workforce (PSW). Working Group report. $\mathrm{NIH}$ web site, 2014. 2. NIH. biomedical research workforce. 2014. Available: http://acd.od.nih.gov/reports/PSW_Report ACD_ 06042014.pdf [Accessed 3 Feb 2020].

10 Ommering BWC, van Blankenstein FM, Wijnen-Meijer M, et al. Fostering the physician-scientist workforce: a prospective cohort study to investigate the effect of undergraduate medical students' motivation for research on actual research involvement. BMJ Open 2019;9:e028034.

11 Amgad M, Man Kin Tsui M, Liptrott SJ, et al. Medical student research: an integrated mixed-methods systematic review and metaanalysis. PLoS One 2015;10:e0127470.

12 de Jong PGM, Haramati A. Teaching to develop scientific engagement in medical students. In: Huggett KN, Jeffries WB, eds. An introduction to medical teaching. Dordrecht: Springer Science + Business Media, 2014 
13 Bierer SB, Chen HC. How to measure success: the impact of scholarly concentrations on students--a literature review. Acad Med 2010;85:438-52.

14 Radville L, Aldous A, Arnold J, et al. Outcomes from an elective medical student research scholarly concentration program. J Investig Med 2019;67:1018-23.

15 DiBiase RM, Beach MC, Carrese JA, et al. A medical student scholarly concentrations program: scholarly self-efficacy and impact on future research activities. Med Educ Online 2020;25:1786210.

16 Havnaer AG, Chen AJ, Greenberg PB. Scholarly concentration programs and medical student research productivity: a systematic review. Perspect Med Educ 2017;6:216-26.

17 Kool A, Mainhard T, Jaarsma D, et al. Effects of honours programme participation in higher education: a propensity score matching approach. Higher Education Research \& Development 2017;36:1222-36.

18 Ommering BWC, Wijnen-Meijer M, Dolmans DHJM, et al. Promoting positive perceptions of and motivation for research among undergraduate medical students to stimulate future research involvement: a grounded theory study. BMC Med Educ 2020;20:204

19 Ajzen I. The theory of planned behavior. Organ Behav Hum Decis Process 1991;50:179-211.

20 Bandura A. Self-efficacy. The exercise of control. New York: Freeman, 1997.

21 Weaver AN, McCaw TR, Fifolt M, et al. Impact of elective versus required medical school research experiences on career outcomes. $J$ Investig Med 2017;65:942-8.

22 Herwaarden CLA, Laan R, Leunissen R. Raamplan artsopleiding 2009. Nederlandse Federatie van Universitair Medische Centra (NFU), 2009.

23 Richardson D, Oswald A, Lang E. The CanMEDS 2015 Scholar expert Working group ReportThe CanMEDS 2015 Scholar expert Working
Group report. Ottawa: The Royal College of Physicians and Surgeons of Canada, 2014

24 Ommering BWC, van den Elsen PJ, van der Zee J, et al. Using an extracurricular Honors program to engage future physicians into scientific research in early stages of medical training. Med Sci Educ 2018;28:451-5

25 Ryan RM, Deci EL. Self-determination theory: basic psychological needs in motivation, development, and wellness. Guilford Publications, 2017.

26 Schwarzer R, Jerusalem M. Generalized self-efficacy scale. In: Weinman J, Wright S, Johnston M, eds. Measures in health psychology: a user's portfolio. Causal and control beliefs. Windsor, UK: NFER-NELSON, 1995: 35-7.

27 Midgley C, Maehr ML, Hruda LZ. Manual for the patterns of adaptive learning scales (PALS). Ann Arbor: University of Michigan, 2000.

28 Vereijken MWC, van der Rijst RM, de Beaufort AJ. Fostering firstyear student learning through research integration into teaching: student perceptions, beliefs about the value of research and student achievement. Innovations in Education and Teaching International 2016:1-8

29 Litman JA. Interest and deprivation factors of epistemic curiosity. Pers Individ Dif 2008;44:1585-95.

30 Netten AP, Dekker FW, Rieffe C, et al. Missing Data in the Field of Otorhinolaryngology and Head \& Neck Surgery: Need for Improvement. Ear Hear 2017;38:1-6.

31 Waaijer CJF, Ommering BWC, van der Wurff LJ, et al. Scientific activity by medical students: the relationship between academic publishing during medical school and publication careers after graduation. Perspect Med Educ 2019;8:223-9.

32 Ranieri V, Barratt H, Fulop N, et al. Factors that influence caree progression among postdoctoral clinical academics: a scoping review of the literature. BMJ Open 2016;6:e013523. 